\title{
Water Quality and Consumer Perception of Reverse Osmosis Filtered Water. A Study in Chronic Kidney Disease Endemic Region in Anuradhapura District, Sri Lanka.
}

\author{
M.G.T.S. Amarasekara ${ }^{1}$, W.M.T.K. Wijesundara ${ }^{2}$ and \\ D.M.S.H. Dissanayaka ${ }^{3}$ \\ ${ }^{1,2,3}$ Faculty of Agriculture, Rajarata University of Sri Lanka, \\ Puliyankulama, Anuradhapura, Sri Lanka.
}

\begin{abstract}
Providing safe drinking water has been suggested as a primary preventive measure for Chronic Kidney Disease (CKD) prevails in Anuradhapura district, Sri Lanka. In response to this, Reverse Osmosis (RO) water has been introduced as an alternative form of drinking water in areas where CKD is endemic. This study aimed to assess water quality and consumer perception of RO filtered water in Anuradhapura district, Sri Lanka. Forty RO plants were selected from four categories for water quality analysis. A detailed questionnaire survey was conducted using 200 consumers and 40 RO plant operators to assess consumer perspectives and maintenance procedures. Quality parameters of RO filtered water were within the WHO standards except some elevated levels of total coliform reported in some school and domestic level RO plants. Most of the community and commercial based RO plants followed proper operational and maintenance procedures. However, maintenance is weak in school level RO plants and some domestic plants. About $95 \%$ of the consumers of surveyed sample were totally satisfied with the quality of RO water and a significant improvement was observed in volume of water intake (from $1.54 \pm 0.6$ to $2.8 \pm 1.2$ liters $(\mathrm{p}<0.05)$ after introducing of $\mathrm{RO}$ plants.

Keywords: Chronic Kidney Disease, Consumer Satisfaction, Reverse Osmosis Plants, Water Quality
\end{abstract}

\section{Introduction}

Chronic Kidney Disease (CKD) is one of the major health issues in Sri Lanka. The disease is mainly reported in Anuradhapura district in the North
Central Province (NCP) of the country (Rajapakse, et al., 2016). It is now confirmed that CKD appears without pre-existing conditions such as hypertension and diabetes, and therefore the disease is believed as attributed to external environmental factors (Wimalawansa, 2014). Most of the studies have been resulted various hypotheses on environmental factors associated with the occurrence of CKD. According to Gunathilaka, et al., (2014) unknown CKD is an environmental-exposure disease caused by multiple factors such as chronic exposure to kidney damaging pesticides, arsenic, lead, cadmium, poor diet and genetic susceptibility to kidney failure. Some studies revealed that the CKD has a closer relationship with drinking water in NCP (Jayasumana, et al., 2014). Most of the people in NCP utilized groundwater for their drinking purpose during last 04 decades. National Water Supply \& Drainage Board (NWSDB) supplies water for people in urban areas and people in rural areas use water from dug wells and surface water sources. Water quality studies suggested that high level of fluoride, total dissolved solids including hazardous elements, and the high saline nature can be the major factors affect on increasing CKD incidences reported in the NCP, Sri Lanka (Dissanayake, 2005). In response to this, RO water has been introduced as an alternative form of drinking water in areas where CKD is endemic. Reverse Osmosis plants were installed by different agencies such as the National Water Supply \& Drainage Board (NWS\&DB), NGOs and private organizations to provide clean drinking water to rural communities dwelled in CKD prevailing areas of NCP. Even though, there has effective purifying 
ability, the standard operation and maintenance procedures of the RO systems are very important to ensure the long last water quality and to keep entire lifespan. Maintenance procedures and quality management practices of RO plants tend to vary from an operator to another (Jayasumana et al., 2016). Therefore, it is necessary to monitor the water quality analysis along with the maintenance of RO system. Findings on the deviations in procedures of operation and maintenance of $\mathrm{RO}$ plants might be used in find solutions for health issues in the future. In addition understanding the perception of consumer is very essential for further development of RO plants.

However, there is no proper mechanism to investigate the effectiveness with the management strategies and maintenance of the established RO plants specially private sector installed and domestic level RO plants. Hence this study was conducted to assess the quality of drinking water purified by the RO systems and find out perceptions of consumers on water purified by RO plants.

\section{Materials and Methods}

Forty RO plants were selected based on four categories namely; community, school, domestic and commercial levels as shown in table 01. Water samples were collected in one-month interval during period of six months.

\subsection{Water sample analysis}

Water quality parameters such as $\mathrm{pH}$, Electrical Conductivity(EC), Total Dissolved Solids(TDS), Sodium (Na), Potassium (K), Calcium (Ca), Magnesium (Mg), Arsenic (As), Cadmium (Cd) and Lead $(\mathrm{Pb})$ of collected water samples were measured in the Soil and Science Laboratory, Department of Agricultural Engineering and Soil Science, Faculty of Agriculture, Rajarata University of Sri Lanka. Chlorides $\left(\mathrm{Cl}^{-}\right)$, Fluorides $\left(\mathrm{F}^{-}\right)$and Total Coliform were determined in the Regional Laboratory of National Water Supply and Drainage Board (NWS\&DB) in Anuradhapura, Sri Lanka. Table 02 shows measured parameters and methods of analysis. Water quality parameters were compared with the WHO standards and Excel graphs were used to show those comparisons graphically. The data from questionnaires was analyzed using Statistical Package for the Social Sciences (SPSS) version 22 and descriptive statistics and paired t-test were used as methods of statistical analysis.

Table 01: RO plants selected for the study

\begin{tabular}{lll}
\hline Type of RO plant & $\begin{array}{l}\text { Selected } \\
\text { number }\end{array}$ & Remarks \\
\hline Community level & 10 & $\begin{array}{l}\text { Established by NWS\&DB. Maintained by community } \\
\text { based organizations. Capacity 750- } 1000 \text { L/ day }\end{array}$
\end{tabular}

2. Commercial level

3. Schools level

4. Domestic level
10
Established and maintained by owners with the technical support from sole agent. Capacity 750 - 1000 L/day

Established by different agencies and maintained by parent associations. Capacity 750 - 1000 L/day

Supply and installed by agents and maintained by households. Capacity 5- 10 L/day 
Table 02: Analytical parameters of water quality

\begin{tabular}{ll} 
Water quality parameters & Method of analysis \\
\hline $\mathrm{pH}$ & Multi parameter analyzer (HACH: Sension 156) \\
Electrical Conductivity (EC) & Multi parameter analyzer (HACH: Sension 156) \\
Total Dissolved Solids (TDS) & Multi parameter analyzer (HACH: Sension 156) \\
Sodium & Flame photometer (Sherwood model 360) \\
Potassium & Flame photometer (Sherwood model 360) \\
Calcium & Flame photometer (Sherwood model 360) \\
Magnesium & Atomic absorption spectrophotometer (Model:BUCK \\
Fluoride & scientific) \\
Chloride & Spectrophotometer (HACH DR 5000) \\
Cadmium , Arsenic and Lead & Acidic nitrate titration \\
Total coliform & Inductively Coupled Plasma Optical Emission \\
\hline
\end{tabular}

\section{Results and Discussion}

Though RO purified water had introduced as a preventive measure for $\mathrm{CKD}$, the quality of water should be frequently analyzed to ensure the healthcare of consumers because it can be varied with the operation and maintenance procedures of $\mathrm{RO}$ plants. Water quality parameters such as $\mathrm{pH}$, Electrical conductivity (EC), Total Dissolved Solids (TDS), Sodium(Na), Potassium(K), Calcium(Ca), Magnesium( $\mathrm{Mg})$, Chloride $(\mathrm{Cl})$, Fluoride (F), hazardous elements such as Cadmium(Cd), Arsenic (As) and Lead $(\mathrm{Pb})$ and total Coliform as a biological parameter are measured.

\section{1 pH, EC and TDS of filtered water}

$\mathrm{pH}$ is an important parameter in evaluating acidic or alkaline nature of drinking water. WHO has recommended permissible limits of $\mathrm{pH}$ from 6.5 to 8.5 of water for drinking purpose. The mean $\mathrm{pH}$ values of purified water in all four categories varied from 6.7 to 7.2 (Table 03). Hence, most of the RO plants in all four categories were within the WHO standards. However, several community level and school level RO plants showed slightly deviated $\mathrm{pH}$ values from minimum WHO standards. In general $\mathrm{pH}$ value of purified water in all tested RO plants were well within the suitable range for drinking purpose.

The amount of dissolved solids in water determines the Electrical Conductivity (EC). Increase in ions concentration enhances the electrical conductivity of water. The maximum permissible level of $\mathrm{EC}$ in drinking water is $750 \mu \mathrm{S} / \mathrm{cm}$ according to $\mathrm{WHO}$ standards. Purified water in all RO plants existed in the range of 125 to $192 \mu \mathrm{S} / \mathrm{cm}$ indicating far below the maximum permissible level (Table 03).

Water has the ability to dissolve a wide range of inorganic and organic substances. These substances produced un-wanted taste and diluted color in appearance of water (Dhammawardana, et al, 2015). The water with high Total Dissolved Solids (TDS) value indicates that water has more dissolved inorganic and organic substances. Inorganic substances include water soluble ions and salts. Therefore, TDS represents soluble substances in water and it is one of the major factors affecting the taste and the appearance of drinking water (WHO, 2011). Mean TDS values of $\mathrm{RO}$ purified water were within the range of 255 to 423 ppm. According to the WHO standards maximum permissible level of TDS to be present in drinking water is $500 \mathrm{ppm}$. It clearly exhibited that measured values of purified water in all RO plants were below the maximum permissible level. However, Jayasumana et al., (2016) reported much lower TDS (range 9-65 ppm) of filtered water in large and medium scale RO plants in NCP, Sri Lanka.

\subsection{Dissolved ions presence in filtered water}

The mean values of measured ions (sodium, calcium, magnesium, chloride and fluoride) with standard deviations $( \pm)$ are shown in table 03 . These ions are essential to human health and are involved in many functions in metabolism (Chandrajith, et al., 2011). After having meals, mineral-rich drinking-waters may need for the fulfillment of total intakes of these nutrients. Occasionally, the higher levels of these than 
recommended can be also affected adversely to the human health. Especially higher level of fluoride in drinking water cause detrimental effects on human health (Dissanayaka, 2005).

The sodium contents found were in the range of 5 $46 \mathrm{mg} / \mathrm{l}$ in tested RO purified water samples in all four categories. All the values were well below the WHO permissible level. Sodium may affect the taste of drinking-water at levels above about 200 $\mathrm{mg} / \mathrm{l}$. Hence there is no any adverse effect of existing $\mathrm{Na}$ content on quality and the taste of all tested RO purified samples. Similarly, Ca (range 12- $42 \mathrm{ppm}) \mathrm{Mg}$ (range 8-14 ppm), $\mathrm{Cl}$ (range 12-38 $\mathrm{ppm}$ ), F ( range 0.2-0.4 ppm) contents reported as mean values of 4 categories of RO purified water were below the maximum level recommended by the WHO.

Table 03. Mean values of measured parameters of RO filtered water

\begin{tabular}{lllllllll}
\hline Type of RO plant & $\mathrm{pH}$ & $\mathrm{EC}$ & $\mathrm{TDS}$ & $\mathrm{Na}$ & $\mathrm{Ca}$ & $\mathrm{Mg}$ & $\mathrm{Cl}$ & $\mathrm{F}$ \\
& & $\mu \mathrm{S} / \mathrm{cm}$ & $\mathrm{ppm}$ & $\mathrm{ppm}$ & $\mathrm{ppm}$ & $\mathrm{ppm}$ & $\mathrm{ppm}$ & $\mathrm{ppm}$ \\
\hline Community level & $6.7 \pm 0.5$ & $125 \pm 08$ & $255 \pm 12$ & $18 \pm 02$ & $12 \pm 02$ & $08 \pm 03$ & $12 \pm 02$ & $0.2 \pm 0.1$ \\
Commercial level & $6.9 \pm 0.7$ & $145 \pm 10$ & $304 \pm 04$ & $24 \pm 03$ & $18 \pm 03$ & $10 \pm 02$ & $16 \pm 0.5$ & $0.4 \pm 0.2$ \\
School level & $7.2 \pm 0.6$ & $189 \pm 12$ & $387 \pm 14$ & $32 \pm 03$ & $42 \pm 02$ & $14 \pm 03$ & $38 \pm 03$ & $0.6 \pm 0.2$ \\
Domestic level & $6.9 \pm 0.4$ & $192 \pm 11$ & $423 \pm 07$ & $39 \pm 02$ & $22 \pm 01$ & $13 \pm 02$ & $36 \pm 02$ & $0.4 \pm 0.1$ \\
Max. permissible & 8.5 & 750 & 500 & 200 & 100 & 50 & 250 & 1.5 \\
level (WHO, 2011) & & & & & & & & \\
\hline
\end{tabular}

\subsection{Hazardous elements presence in filtered water}

Elements such as Arsenic (As), Lead (Pb) and Cadmium $(\mathrm{Cd})$ are the most hazardous in small concentrations and those have identified as an attributed factors to CKD in Sri Lanka. It has been reported that As is one contributing factor of CKD. Figure 01 (a) illustrates mean As contents of all individual RO plants and maximum WHO permissible level of As for drinking water. Analytical results indicated that As contents varied in a range of non-detectable to $0.006 \mathrm{mg} / \mathrm{l}$. It

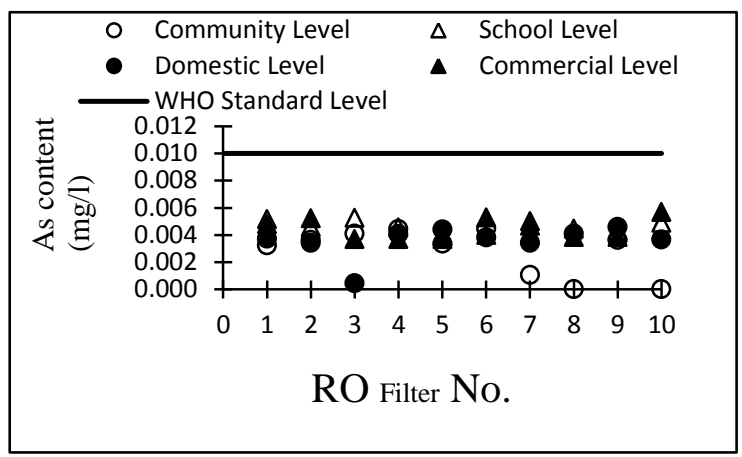

Figure 01 (a) Arsenic clearly reveals that As contents reported in all tested RO purified water samples remained much below the permissible level of $0.01 \mathrm{mg} / \mathrm{l}$.

Lead is a heavy metal which is suspected to be another causative factor of CKD. Mean $\mathrm{Pb}$ contents reported in water samples collected from individual RO plants with WHO maximum permissible level are illustrated in figure 01 (b). It also indicated that all tested water samples had $\mathrm{Pb}$ content below WHO maximum permissible level of $0.01 \mathrm{mg} / \mathrm{l}$. Lead content of all tested samples were within the range of non-detectable to $0.004 \mathrm{mg} / \mathrm{l}$.

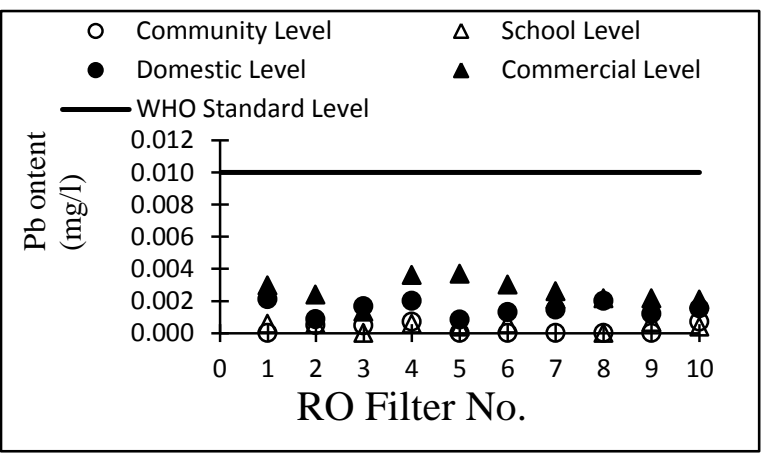

Figure 01 (b) Lead 


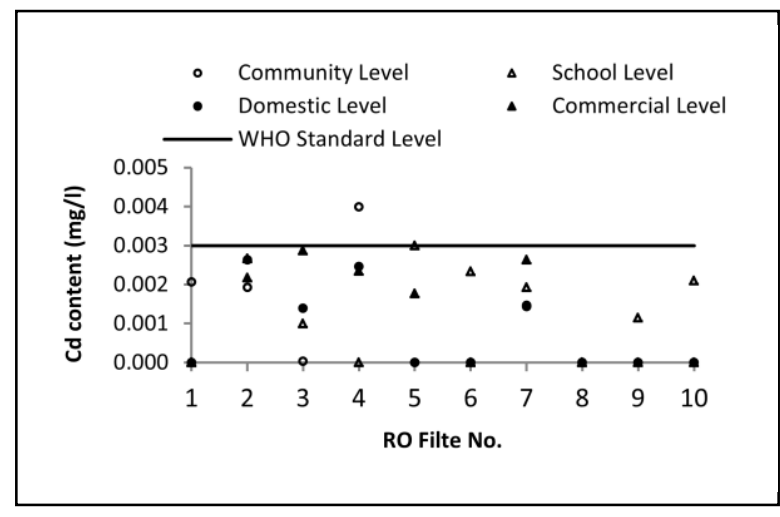

Figure 01 (c) Cadmium

Cadmium causes many adverse impacts on human health due to its half-life of 15-20 years (Averbeck and Bertin, 2006). Higher Cd content in drinking water sources may have resulted kidney failures (Bandara, et al., 2008). Therefore, Cd content in RO purified water should be assessed in regular intervals. Figure 01(c) presents mean $\mathrm{Cd}$ concentrations in water, sampled from individual RO plants. Except one community level RO plant, all others showed less Cd contents compared to maximum permissible level $(0.003 \mathrm{mg} / \mathrm{l})$ given by WHO.

\subsection{Total coliform presence in filtered water}

Presence of coliform bacteria in drinking water is warned that the unsuitability of water for drinking due to the disease-causing ability of those organism. According to the WHO standards for drinking water, total coliform value should be less than three (WHO, 2011). Total coliform was not detected in filtered water in community and commercial level RO plants. However, some of the water samples taken from school and domestic level RO plants showed higher coliform contents than the WHO recommended level (Fig. 01 (d)). Reverse osmosis purifiers have a filter which contained active carbon and an ion exchange resins. This filter should be washed or exchanged periodically. After a certain time filters get saturated and should be exchanged. If they are not exchanged within a proper time, bacteria adsorbed on filter will enter the drinking water again (Van der Bruggen, et al., 2009). Therefore, possible reasons for bacterial contamination could be poor maintenance and incorrect operations due to lack of proper supervision.

\subsection{Perception of previous water source}

Jayasumana et al., (2015) reported that people who consume water from shallow wells and abandoned dug wells are at a high risk of developing CKD.

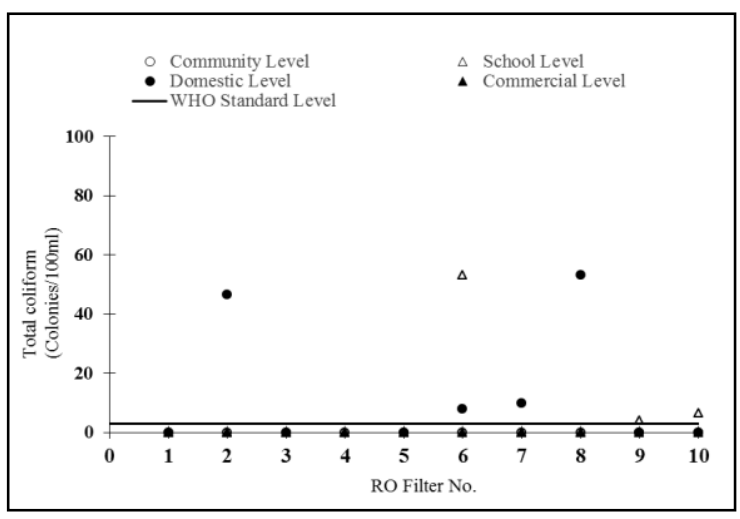

Figure 01 (d): Total coliform

Dug wells, tube wells, pipe-borne water, springs, rain and bottled water were the major drinking sources previously used by the people in the study area. According to the questionnaire survey, about $59.5 \%$ of studied sample used water from dug wells, $19.5 \%$ from pipe-borne water and $11.5 \%$ from tube wells previously for all of their day today activities (Fig. 02). However, newly settled families have used RO filtered water from the beginning of the settlement.

Most of the consumers had a bad impression about previous water sources. About $57 \%$ of consumers felt it was bad and 9\% was very bad. According to that, $66 \%$ of consumers have used previous drinking water source without total satisfaction. Bad taste, bad colour, bad odour, no consistent water source, distance to water source from residence and spreading of CKD were their reasons for abandoning of previous water sources and however, the most common reasons were CKD and bad taste of water.

\subsection{Consumer perception of RO filtered water}

Figure 03 illustrates consumer perception of RO filtered water. Results showed that $58 \%$ respondents believe that the quality of RO filtered water is very good and other $41 \%$ responded that water quality is good. One percent of the total respondents stated the quality of RO purified water is poor. All most all respondents had good education background and better awareness on water quality. Besides educational levels, gender difference, such as a sense of vulnerability sensed by women is another factor affecting perception of water quality (De França, 2010). All female respondents in the sample stated that quality of RO filtered water is extremely good. 


\subsection{Consumer satisfaction on RO purified water}

Nearly $95 \%$ of sampled consumers were highly satisfied with the quality and distribution process of RO filtered water (Fig. 04). They are satisfied with taste, odour and safety of water. Only 5\% had different opinions. Satisfaction is dependent on the household income and comparatively lower income group satisfies more. Consumers with better income prefer some popular branded bottled water available in the super markets than the RO purified water distributed by community based organizations.

\subsection{Amount of Water Intake}

Significantly higher percentage of CKD patients has found to be working more than 6 hrs. per day under the sun and they were not drunk recommended amount of water (Petrusevski et al.,

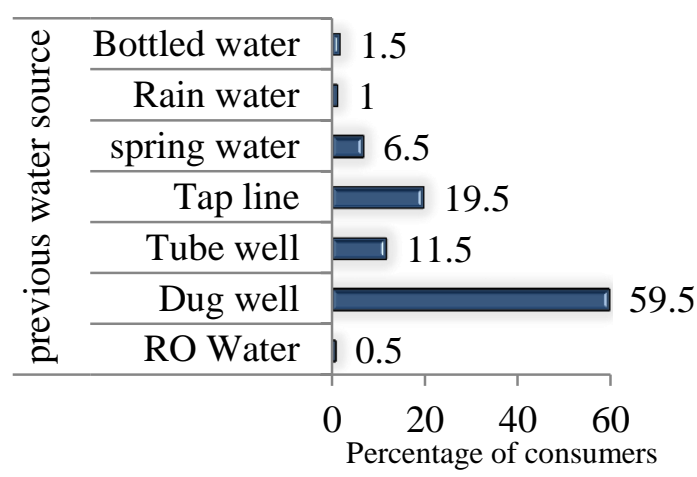

Figure 02: Consumer usage of previous water sources

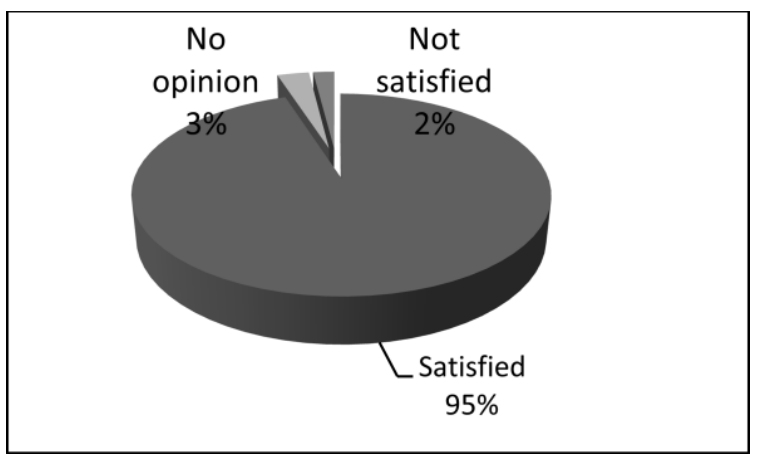

Figure 04: Consumer satisfaction

3.9 Perception on RO water by CKD patients Within the selected sample, there were $15.5 \%$ CKD patients. According to their purview change in the source of drinking water from previous sources to
2007). The recommended minimum requirement of water intake is $2-3 \mathrm{~L} /$ day for one person to function of body well. However, results of the study indicated, a highest percentage of individual $(62.5 \%)$ has consumed average value of $1.5 \mathrm{~L} /$ day at the previous situation. Low consumption of water is attributed to bad taste and increased hardness. Insufficient consumption of water has resulted dehydration among farming community who worked open fields under high temperature. After the introducing RO purified water, there has a good propensity to drink more water frequently because of the good taste and softness. The survey results exhibited that water intake has gone up significantly when they started to consume RO filtered water. About $66 \%$ has consumed more than $2.8( \pm 1.2) \mathrm{L}$ of water and statistically it has a significant improvement $(\mathrm{p}<0.05)$ compared to previous intake of $1.54( \pm 0.6) \mathrm{L}$ (Fig. 05).

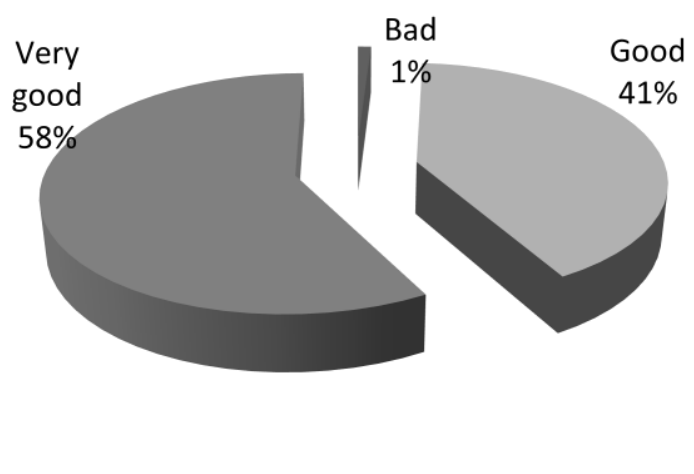

Figure 03 - Consumer perception of RO water

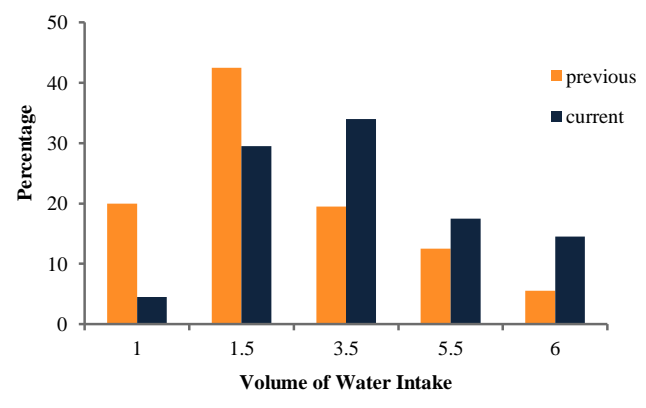

Figure 05: Water intake by sampled community

RO purified water have contributed to control the CKD in a considerable extent. About $9 \%$ out of $15.5 \%$ patients have agreed with the RO purified water as a solution for CKD. Further $57.5 \%$ of total 
sample believed that there is a clear reduction of spreading CKD in their region during past couple of years after introducing RO filtered water.

The survey further elaborated that, $24 \%$ of consumers have suffered several water related health issues in addition to CKD during the period in which previous water sources were used. Those health issues were urinary infections, stomachaches and dental fluorosis. However it has reduced to $6 \%$ when they have changed their water source.

\subsection{Maintenance of RO plants}

Mostly, the maintenance of RO system has been mentioned as a drawback. Since all water filters require maintenance at different intervals and different brands have different maintenance requirements. Usually, all water filter cartridges including RO water filters must be replaced at least twice a year. All community level RO plants follow proper operational and maintenance procedures. National Water Supply \& Drainage Board has taken the responsibility of guidance at the maintenance of all community level RO plants and they have given a better training for all operators of those RO plants. Therefore, most of RO plants are existed at proper conditions and provided good quality water. Many of the community based RO plants provide water for nominal price (Rs. 1-2 per liter). The collected funds through selling water are used to pay for the caretaker and meet the cost of maintenance. Since funds are available, community based RO filters have set time frame for cleaning and replacing filters.

In commercial level RO plants water is sold at Rs. 2.00 per liter. These plant operators are responsible at the health of large number of people and therefore, they have being under the restrictions of Public Health Inspectors of the area. Most of the RO plant operators were well trained and hence, commercial level RO plants are also existed under good condition.

School based RO plants provide water totally free of charge and hence no such kind of financial support. These plants are maintained by parent teacher associations through facilities fees collected from students and some donations. Most probably plant operators are parents and they are not properly trained. Therefore, this process has many lapses and hence maintenance of school based RO plants are not up to the expected level.

Maintenance of domestic level RO plants are mostly done by technicians of relevant companies. Since owners should pay for this service, they are reluctant to get the service from technicians.
Findings of the questionnaire survey revealed that about $75 \%$ owners attend themselves to clean the filters and other minor repairs. Hence, most of the domestic RO plants are not maintained according to manufactures guidelines. .

\section{Conclusions}

Water quality Parameters such as pH, EC, TDS, $\mathrm{Na}, \mathrm{Ca}, \mathrm{Mg}, \mathrm{Cl}, \mathrm{F}, \mathrm{As}, \mathrm{Cd}$ and $\mathrm{Pb}$ of $\mathrm{RO}$ purified water are within WHO standard level of drinking water. Total coliform levels of some school and domestic level plants exceeded the WHO standards. Color, odor, taste and softness are major physical parameters of drinking water quality that consumers are mostly concerned. Consumers prefer to consume more water due to the softness of RO purified water and there is a statistically significant improvement in water intake of consumers than previous situation. Though, maintenance is weak in domestic and school level RO plants, community level and commercial level RO plant operators follow proper operational and maintenance procedures.

\section{References}

[1] Averbeck, D. and Bertin, G. (2006). Cadmium: cellular effects modification of biomolecules, modulation of DNA repair and genotoxic consequences. (A review). Biochimie. 88, 1549-1559.

[2] Bandara, J. M. R. S., Senevirathna, D. M. A. N., Dasanayake, D. M. R. S. B., Herath, V., Bandara, J. M. R. P., Abeysekara, T. and Rajapaksha, K. H. (2008). Chronic renal failure among farm families in cascade irrigation systems in Sri Lanka associated with elevated dietary cadmium levels in rice and freshwater fish (Tilapia). Environmental Geochemistry and Health. 30(5): 465-478.

[3] Chandrajith, R., Dissanayake, C. B., Ariyarathna, T., Herath, H., M. J. M. K., \& Padmasiri, J. P., (2011). Dose-dependent Na and $\mathrm{Ca}$ in fluoride-rich drinking water another major cause of chronic renal failure in tropical arid regions. Science of the Total Environment. 409(4): 671-675.

[4] De França Doria M. (2010). Factors influencing public perception of drinking water quality. Water Policy. 12(1): 1-19.

[5] Dharmawardana, M. W. C., Amarasiri, S. L., Dharmawardene,N., and Panabokke, C. R. (2015). Chronic kidney disease of unknown aetiology and ground-water ionicity: Study 
based on Sri Lanka. Environmental Geochemistry and Health. 37(2): 221-231.

[6] Dissanayake C.B, (2005). Water quality in dry zone of Sri Lanka- some interesting health aspects, Journal of the National Science foundation of Sri Lanka. 33(3):161-168.

[7] Gunatilake S.K., Samaratunga S.S. and Rubasinghe R.T., (2014). Chronic Kidney Disease (CKD) in Sri Lanka - Current Research Evidence Justification: A Review, Sabaragamuwa University Journal, 13(2): 3158.

[8] Jayasumana C., Gunatilake S. and Senanayake P. (2014). Glyphosate, hard water and nephrotoxic metals: are they the culprits behind the epidemic of chronic kidney disease of unknown etiology in Sri Lanka? Int J Environ Res Public Health. 11:2125-47.

[9] Jayasumana C., Paranagama P., Agampodi S., Wijewardane C., Gunatilake S. and Siribaddana S. (2015). Drinking well water and occupational exposure to Herbicides is associated with chronic kidney disease, in Padavi-Sripura, Sri Lanka, Environmental Health Journal. 14 (6).

[10] Jayasumana C., Ranasinghe O., Ranasinghe S., Siriwardhana I., Gunathilake S., Siribaddana S., (2016). Reverse osmosis plant maintenance and efficacy in chronic kidney disease endemic region in Sri Lanka, Environmental Health and Preventive Medicine. 21: (6).

[11] Petrusevski B., Sharma S., Schippers J. C. and Shordt K. (2007). Arsenic in Drinking Water. IRC International Water and Sanitation Centre, Delft, 17.

[12] Rajapakse S., Shivanthan,M.C. and Selvarajah. M.(2016). Chronic kidney disease of unknown etiology in Sri Lanka. Int J. Occup Environ Health. 22(3): 259-264.

[13] Van der Bruggen B, Goossens H, Everard P, Stemgee K, Rogge W. (2009). Cost-benefit analysis of central softening for production of drinking water. J Environ Manage. 91(2): 541549.

[14] WHO (2011). Guidelines for Drinking - Water Quality, 4th edn. World Health Organization, Geneva, Switzerland.

[15] Wimalawansa S.J. (2014). Escalating chronic kidney diseases of multi-factorial origin in Sri Lanka: causes, solutions, and recommendations. Environmental Health and Preventive Medicine.19:375-94. 